Ciência e Natura, Santa Maria, v. 37 n. 4 set-dez. 2015, p. 405-421

Revista do Centro de Ciências Naturais e Exatas - UFSM

ISSN impressa: 0100-8307 ISSN on-line: 2179-460X

\title{
ciênciaenatura
}

\section{Análise de Parâmetros Morfométricos da Bacia Hidrográfica do Arroio Lajeado Grande (RS)}

\author{
Analysis of Morphometric Parameters in the Basin of Arroio Lajeado Grande (RS) \\ Igor da Silva Knierin, Romario Trentin
}

Universidade Federal de Santa Maria, YFSM, Santa Maria, RS, Brasil.

\section{Resumo}

O uso de parâmetros morfométricos para avaliações de bacias hidrográficas apresenta-se como importante instrumento de análise possibilitando o desenvolvimento do estudo das características físicas do ambiente. Inserido neste contexto, o presente artigo tem como objetivo realizar a análise de parâmetros morfométricos da Bacia Hidrográfica do Arroio Lajeado

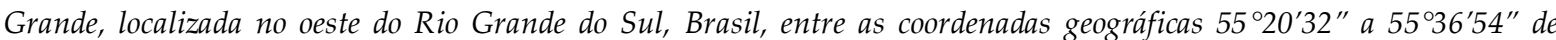
longitude oeste e 29 $9^{\circ} 6^{\prime} 47^{\prime \prime}$ a 29 59'50" de latitude sul. Metodologicamente, o estudo desenvolveu-se através da revisão da literatura e, por conseguinte, com a análise dos parâmetros morfométricos da área de estudo definidos com: ordenamento dos canais fluviais, padrão de drenagem, densidade de drenagem, extensão média do escoamento superficial, sinuosidade do curso d'água, coeficiente de manutenção, indice de circularidade, hipsometria, declividade e comprimento de vertentes. Como resultados, destacou-se a influência que a constituição litológica desempenha na área de estudo, em que desponta-se diretamente sobre o número total e distribuição dos segmentos de canais, observou-se também uma área não muito suscetível a cheias. Frente a isso, o estudo permitiu através de uma análise quantitativa avaliar a parametrização morfomética destacando-se a aplicabilidade destas informações ao planejamento, na tomada de ações prognósticas associadas ao uso e ocupação da terra.

Palavras-chave: Morfometria. Estudos Ambientais. Bacia Hidrográfica. Oeste do RS. Arroio Lajeado Grande - RS

\begin{abstract}
The use of morphometric parameters for assessment of river basin presents itself as an important analysis tool enabling the development of the study of the physical characteristics of the environment. In this context, this paper aims to conduct analysis of morphometric parameters of the Basin of the Arroio Lajeado Grande, located in the west of the Rio Grande do

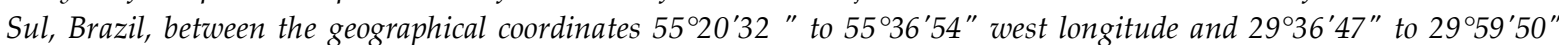
south latitude. Methodologically, the study was developed through literature review and, consequently, with the analysis of morphometric parameters of the study area defined with: system of fluvial channels, drainage standard, drainage density, average length of runoff, sinuosity the watercourse, maintenance coefficient, index of circularity, hypsometry, slope and length of strands. As results stood out the influence that the lithological constitution plays in the study area, where it emerges directly on the total number and distribution of channels segments, it was also observed an area a little susceptible to flooding. Given this, the study allowed through a quantitative analysis to evaluate the morphometric parameterization highlighting the applicability of this information in planning, in taking prognostic actions associated with the use and occupation of land.
\end{abstract}

Keywords: Morphometry. Environmental Studies. Hydrographic Basin. West of the RS. Arroio Lajeado Grande - RS 


\section{Introdução}

Os estudos morfométricos de bacias hidrográficas apresentam-se como importantes ferramentas para $\mathrm{o}$ planejamento e gestão, uma vez que, permitem através de técnicas e procedimentos quantitativos detalhar o ambiente destas que se constituem em limites naturais da paisagem, entendidas conforme Botelho e Silva (2004) como célula básica para análises ambientais.

Nesse sentido, dentro de um contexto histórico, Christofoletti (1974) destaca que a análise de bacias hidrográficas passa a apresentar um caráter mais objetivo a partir dos estudos realizados por Horton (1945 apud CHRISTOFOLETTI, 1974), os quais estabelecem um método de análise quantitativo de bacias hidrográficas, proporcionando uma nova concepção metodológica que serviu de referência aos diversos estudos que se seguiram.

Dessa forma, considerando a morfometria, Florenzano (2008, p. 17) define que esta refere-se aos "aspectos quantitativos do relevo" e dentre suas variáveis mais utilizadas, aplicam-se não apenas aos estudos geomorfológicos, mas também geológicos, pedológicos, agronômicos, geotécnicos e ainda integrados do meio ambiente com avaliações de fragilidades e vulnerabilidades de ambientes.

Para Reckziegel e Robaina (2006), os trabalhos desenvolvidos através de índices morfométricos do relevo e rede de drenagem podem ser aplicados como um instrumento base direcionado ao estudo do meio ambiente e para o desenvolvimento de planos de gestão, a fim de estabelecer um uso racional do meio, assim como a compreensão de processos naturais. Já Moreira e Neto (1998) resgatam que a análise desses atributos para o relevo permite a avaliação do grau de energia e ainda a suscetibilidade à ocorrência de processos erosivos e deposicionais.

Seguindo nesta linha, o Laboratório de Geologia Ambiental (LAGEOLAM/UFSM) tem desenvolvido trabalhos com abordagens baseadas na avaliação de parâmetros morfométricos para a caracterização do relevo em bacias hidrográficas do oeste do Estado do Rio Grande do Sul. A partir disso, destacam-se os estudos desenvolvidos por Sangoi et al. (2003) com o mapeamento de "Landforms" para a Bacia Hidrográfica do Rio Inhacundá, RS; o trabalho de Trentin et al. (2004), com o mapeamento de unidades de relevo para o alto curso da Bacia Hidrográfica do Rio Itu, RS; também De Nardin e Robaina (2005), com o mapeamento de unidades de relevo para a Bacia Hidrográfica do Arroio Miracatú, RS; e por fim o estudo Baratto e Trentin (2012), com a análise das unidades de relevo da Bacia Hidrográfica do Arroio Puitã, RS.

Neste sentido o presente trabalho tem como objetivo apresentar a análise dos parâmetros morfométricos da Bacia Hidrográfica do Arroio Lajeado Grande (BHALG).

A bacia hidrográfica localiza-se no Brasil Meridional, no oeste do Rio Grande do Sul, junto aos municípios de Alegrete e Manoel Viana, a qual integra 
a Bacia Hidrográfica do Rio Ibicuí, RS, sendo afluente da margem esquerda do rio Ibicuí. Sua área, situa-se entre as coordenadas geográficas $55^{\circ} 20^{\prime} 32^{\prime \prime}$ a $55^{\circ} 36^{\prime} 54^{\prime \prime}$ de longitude oeste e $29^{\circ} 36^{\prime} 47^{\prime \prime}$ a $29^{\circ} 59^{\prime} 50^{\prime \prime}$ de latitude sul, conforme mostra a Figura 1.

De acordo com Paula (2006), a referida bacia hidrográfica apresenta o substrato rochoso constituído por rochas vulcânicas da Formação Serra Geral, arenitos eólicos da Formação Botucatu, e pela a ocorrência de arenitos fluviais da Formação Guará e arenitos/siltitos da Formação Sanga do Cabral.

Em relação a geomorfologia, Robaina et al. (2010), apresentam a proposta de compartimentação geomorfológica da Bacia Hidrográfica do Rio Ibicuí, onde a área de estudo individualiza-se sobre os compartimentos do Planalto da Campanha e a Depressão do Ibicuí. Para as áreas de Planalto, denota-se formas de relevo ondulado, com altitudes inferiores aos $300 \mathrm{~m}$, as quais marcam uma transição gradual para a Depressão do Ibicuí. Esta, por sua vez, caracterizase pela presença de amplas e alongadas formas com topos convexos, conhecidas regionalmente, por coxilhas onde ocorrem significativos processos de erosão.

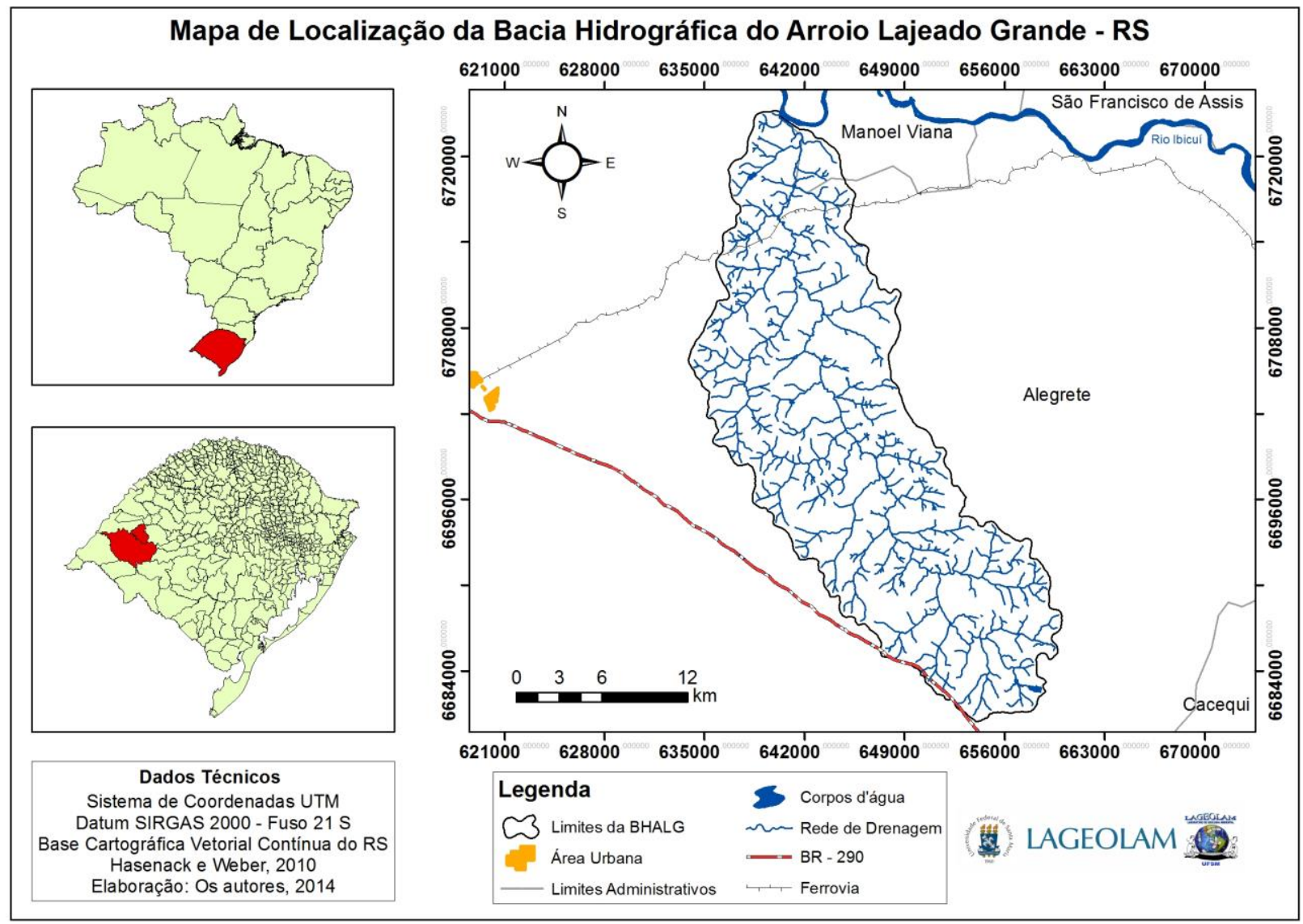

Figura 1: Mapa de localização da Bacia Hidrográfica Arroio Lajeado Grande, RS

Org.: Os autores, 2014 


\section{Material e Método}

Os procedimentos metodológicos que nortearam a elaboração deste artigo foram organizados em duas etapas: a primeira se constituiu na revisão da literatura referente à temática proposta, e a segunda com o trabalho de caracterização e análise dos parâmetros morfométricos da rede de drenagem e do relevo da bacia hidrográfica.

Como base cartográfica, foi utilizada Base Cartográfica Vetorial Contínua do Rio Grande do Sul, em escala 1:50.000, organizada por Hasenack e Weber (2010), que passou por processo de análise e correção das informações em Laboratório. Dessa forma, a partir do ArcGIS versão 10.1, desenvolvido pela ESRI, foram realizadas as análises morfométricas e elaborados os mapas (localização, rede de drenagem, hipsometria e declividade) da área de estudo.

Para análise de comparabilidade frente às características do substrato, relevo e dinâmica superficial, a bacia hidrográfica foi compartimentada em setores de acordo com a variabilidade do terreno e da rede de drenagem, definindo dessa forma três setores: o alto curso, médio curso e baixo curso.

A partir disso, foi realizada a análise dos parâmetros morfométricos da bacia hidrográfica através da avaliação do ordenamento dos canais fluviais, padrão de drenagem, densidade de drenagem, extensão média do escoamento superficial, sinuosidade do curso d'água principal, coeficiente de manutenção, índice de circularidade, hipsometria, declividade e comprimento de vertentes.
Para a definição do ordenamento dos canais fluviais, foi adotada a classificação de Strahler (1952 apud CHISTOFOLETTI, 1974). Nesta classificação, o ordenamento dos canais fluviais se estabelece a partir de segmentos de canais sem tributários, que representam canais de primeira ordem. A confluência de dois canais de primeira ordem resulta em um canal de segunda ordem, assim como a confluência de dois canais de segunda ordem resulta em um canal de terceira ordem e assim de forma sucessiva.

O estabelecimento do padrão de drenagem foi definido conforme Christofoletti (1974) em que é representado através do arranjo espacial dos cursos fluviais mediante a influência de fatores como: atividade morfogenética, disposição das camadas rochosas, resistência litológica variável, diferenças de declividades do terreno e evolução geomorfológica da região.

Com relação à análise da densidade de drenagem (Dd), seguiu-se as proposições de Horton (1945 apud CHRISTOFOLETTI, 1974), apresentadas por Christofoletti (1974) onde se estabelece a relação do comprimento total dos canais fluviais frente à área total da bacia hidrográfica, definida segundo a expressão: $\mathrm{Dd}=\mathrm{Lt} / \mathrm{A}$; em que Dd corresponde a densidade de drenagem, o Lt refere-se ao comprimento total dos canais, e A a área total da bacia hidrográfica.

A extensão média do escoamento superficial $(\ell)$ foi avaliada seguindo as abordagens de Villela e Mattos (1975) que se constituem em uma indicação para estabelecer a distância média para o escoamento superficial das águas, e 
pode ser calculada através da expressão: $\ell=\mathrm{A} / 4 \mathrm{Lt}$; no qual $\ell$ representa a extensão média do escoamento superficial, o A corresponde a área total da bacia hidrográfica e $\mathrm{o} \quad \mathrm{Lt} \quad \mathrm{o}$ comprimento total dos canais.

Com relação à sinuosidade do curso d'água (Sin) da bacia hidrográfica, adaptou-se as definições de Villela e Mattos (1975), onde estabeleceu-se a relação entre o comprimento do canal principal e o comprimento axial da bacia hidrográfica os quais, podem ser calculados através da expressão: $\operatorname{Sin}=$ $\mathrm{Lcc} / \mathrm{L}$; em que $\operatorname{Sin}$ se refere a sinuosidade do curso d'água, o $L_{C P}$ ao comprimento do canal principal e $\mathrm{L}$ ao comprimento axial da bacia hidrográfica.

Para o Coeficiente de Manutenção (Cm), proposto por Schumm (1956 apud CHRISTOFOLETTI, 1974) e citado por Christofoletti (1974), este apresenta como finalidade estabelecer a área mínima para a manutenção do escoamento de um metro de canal, e pode ser definido conforme a expressão: $\mathrm{Cm}=1 / \mathrm{Dd}^{*} 1000$; no qual $\mathrm{Cm}$ representa o coeficiente de manutenção e o Dd o valor para a densidade de drenagem.

A fim de indicar as formas da bacia hidrográfica, foi realizada a análise do índice de circularidade (Ic) definido por Miller (1953 apud CHRISTOFOLETTI, 1974) e apresentado por Christofoletti (1974), que estabelece a relação entre a área de uma bacia hidrográfica com a área de um círculo com mesmo perímetro ao da bacia, que pode ser definido a partir da expressão: Ic = $\mathrm{A} / \mathrm{Ac}$; onde Ic se refere ao índice de circularidade, o A para a área da bacia e o Ac a um círculo com perímetro igual ao da bacia.

A análise da hipsometria da área de estudo foi realizada de acordo com a variação média das atitudes do relevo estabelecida a partir da distribuição espacial das curvas de nível e dos pontos cotados do terreno. Desse modo foram discriminadas quatro classes hipsométricas, com intervalos de $35 \mathrm{~m}$ para a área de estudo: altitudes inferiores aos $110 \mathrm{~m}$, altitudes entre 110 e $145 \mathrm{~m}$, altitudes entre 145 e $180 \mathrm{~m}$ e altitudes superiores a $180 \mathrm{~m}$.

O estudo das declividades do relevo seguiu-se através da definição de três limites de declividades propostos pelo IPT (1981), e apresentado por Trentin et al. (2004), em $2 \%, 5 \%$ e $15 \%$, onde declividades com limites de $2 \%$ correspondem a áreas muito planas no qual predominam processos de deposição, declividades de 5\% representam áreas limítrofes entre processos de deposição e meteorização, e limites de declividade de $15 \%$ que representam áreas propícias para ocorrência de processos de movimentos de massa e fator limitante para o uso de maquinário agrícola. Dessa forma, foram definidas quatro classes para as declividades da bacia hidrográfica, sendo: declividades inferiores a $2 \%$, declividades entre $2 \%$ e $5 \%$, declividades entre $5 \%$ e $15 \%$ e declividades superiores a $15 \%$.

A análise do comprimento de vertentes foi realizada através do ArcGIS 10.1, por meio da medida manual das distâncias entre os pontos cotados do terreno (divisores de água) até os segmentos de canais fluviais de primeira ordem (fundo do talvegue), 
dos quais foram medidas 35 vertentes para cada setor da bacia hidrográfica (alto, médio e baixo curso).

A fim de estabelecer a classificação dos comprimentos das vertentes da área de estudo em curtas, médias e longas, submeteu-se as medidas obtidas ao tratamento estatístico para a definição das classes de forma que melhor representasse a realidade local. Desta forma, foi definido que o desvio padrão $(398,92)$ apresentou o melhor limiar para a definição das classes. Assim sendo, os limites utilizados para definir as classes foram: menor comprimento de vertente +1 desvio padrão e, menor comprimento de vertente +2 desvios padrão, ficando assim delimitadas as classes de comprimento de vertentes:

- Vertentes curtas: todas as vertentes com comprimentos entre: $246 \mathrm{~m}$ (menor comprimento de vertente medido) e $644,92 \mathrm{~m}(246+398,92)$;

- Vertentes médias: todas as vertentes com comprimentos entre: 644,92 (limite das vertentes curtas) e 1043,83 (246 + $\left.2^{*} 398,92\right)$;

- Vertentes longas: todas as vertentes com comprimentos maiores que 1043,83 m (limite das vertentes médias).

\section{Resultados}

\subsection{Análise da Rede de Drenagem}

A Bacia Hidrográfica do Arroio Lajeado Grande é afluente da margem esquerda do rio Ibicuí a qual drena área total de $491,64 \mathrm{~km}^{2}$, com perímetro de $123,91 \mathrm{~km}$. Sua rede de drenagem possui hierarquia fluvial de $5^{\mathrm{o}}$ ordem conforme a classificação de Strahler (1952 apud CHRISTOFOLETTI, 1974), com orientação do canal principal no sentido sudeste-nordeste em seu alto e médio curso, sofrendo uma inflexão em seu baixo curso redirecionando a orientação do canal principal para o sentido sul-norte até sua foz com o rio Ibicuí (ALVES, 2008).

A rede hidrográfica é composta por 529 segmentos de canais fluviais que juntos apresentam extensão de 592,22 $\mathrm{km}$ e um comprimento médio de 1,12 $\mathrm{km}$. Os segmentos de canais de $1^{\mathrm{o}}$ ordem apresentam-se distribuídos em 398 canais, que somam o comprimento total de $302,68 \mathrm{~km}$ e comprimento médio de $0,76 \mathrm{~km}$. A $2^{\text {o }}$ ordem de drenagem possui 98 segmentos de canais, com comprimento total de 152,41 $\mathrm{km}$ e comprimento médio de $1,56 \mathrm{~km}$. Os segmentos de canais de $3^{\circ}$ ordem totalizam 27, onde apresentam extensão de $69,37 \mathrm{~km}$ e comprimento médio de $2,57 \mathrm{~km}$. Já os segmentos de canais de $4^{\mathrm{o}}$ ordem somam 5, apresentando comprimento total de $20,66 \mathrm{~km}$ e comprimento médio de $4,13 \mathrm{~km}$. A $5^{\mathrm{o}}$ ordem de drenagem corresponde ao segmento do rio principal da bacia hidrográfica e apresenta extensão de 47,10 km (Tabela 1). 
Tabela 1: Valores da rede de drenagem da Bacia Hidrográfica do Arroio Lajeado Grande, RS

\begin{tabular}{cccc}
\hline Hierarquia fluvial & $\begin{array}{c}\text { Número } \\
\text { total de } \\
\text { canais }\end{array}$ & $\begin{array}{c}\text { Comprimento } \\
\text { dos canais }\end{array}$ & $\begin{array}{c}\text { Comprimento } \\
\text { médio dos canais }\end{array}$ \\
\hline Primeira Ordem & 398 & $302,68 \mathrm{~km}$ & $0,76 \mathrm{~km}$ \\
Segunda Ordem & 98 & $152,41 \mathrm{~km}$ & $1,56 \mathrm{~km}$ \\
Terceira Ordem & 27 & $69,37 \mathrm{~km}$ & $2,57 \mathrm{~km}$ \\
Quarta Ordem & 5 & $20,66 \mathrm{~km}$ & $4,13 \mathrm{~km}$ \\
Quinta Ordem & 1 & $47,10 \mathrm{~km}$ & $47,10 \mathrm{~km}$ \\
Total & 529 & $592,22 \mathrm{~km}$ & $1,12 \mathrm{~km}$ \\
\hline
\end{tabular}

Org.: Os autores, 2014

A bacia hidrográfica foi sentido, através dessa subdivisão foi compartimentada em três setores possível apresentar um estudo (Figura 2 e Tabela 2), de acordo com os individualizado a cada setor da bacia atributos do terreno e a rede de hidrográfica, conforme as variabilidades drenagem definindo assim: o alto curso, morfométricas da área em estudo. médio curso e baixo curso. Neste

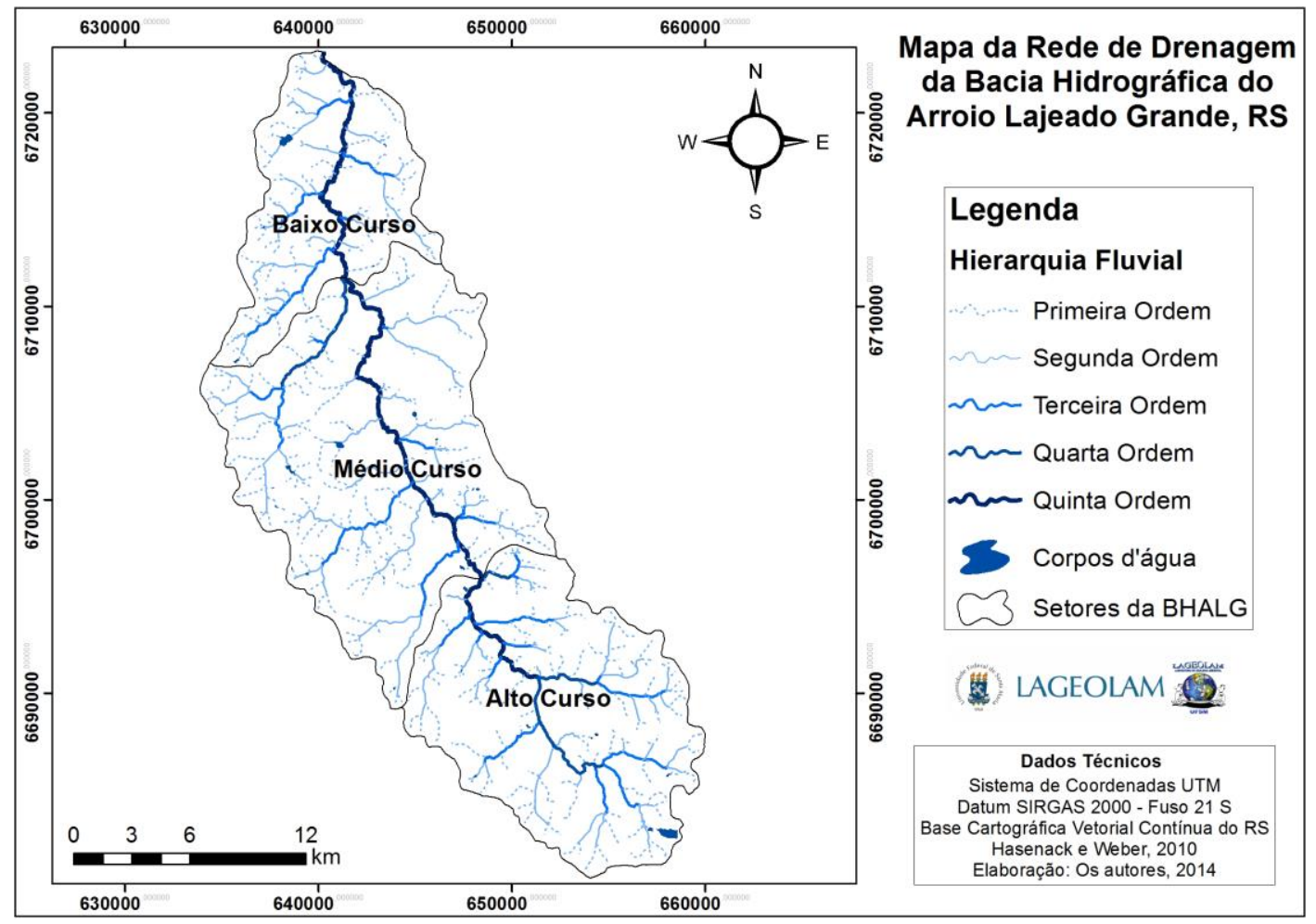

Figura 2: Mapa da rede drenagem e dos setores da Bacia Hidrográfica do Arroio Lajeado Grande, RS

Org.: Os autores, 2014 
O alto curso, localizado na porção sul da bacia hidrográfica, apresenta área total de $170,29 \mathrm{~km}^{2}$, com perímetro de $58,33 \mathrm{~km}$ de extensão. Este setor possui uma hierarquia fluvial de $5^{\mathrm{o}}$ ordem de drenagem, somando ao total 193 segmentos de canais fluviais que correspondem a um comprimento total de 204,66 km, com comprimento médio dos rios de $1,06 \mathrm{~km}$.

$\mathrm{O}$ médio curso encontra-se localizado na porção central da bacia hidrográfica, no qual apresenta como maior ordem de drenagem o segmento do canal principal em $5^{\mathrm{o}}$ ordem. O setor drena uma área total de $223,14 \mathrm{~km}^{2}$, em um perímetro de $74,84 \mathrm{~km}$ e dentre o qual se distribuem 213 segmentos de canais fluviais, somando ao total o comprimento de $255,94 \mathrm{~km}$ de extensão, em um comprimento médio dos rios de $1,20 \mathrm{~km}$.

O baixo curso, localizado na porção norte da área de estudo, drena área total de 98,21 km², com perímetro de 51,77 $\mathrm{km}$. O setor possui como maior hierarquia fluvial o segmento de $5^{\circ}$ ordem de drenagem do canal principal e soma ao total 125 segmentos de canais fluviais, com comprimento total de $131,62 \mathrm{~km}$, em um comprimento médio dos rios de $1,05 \mathrm{~km}$.

Tabela 2: Variáveis da rede de drenagem por setores da Bacia Hidrográfica do Arroio Lajeado Grande, RS

\begin{tabular}{cccccc}
\hline $\begin{array}{c}\text { Setores e } \\
\text { Bacia }\end{array}$ & $\begin{array}{c}\text { Área Total } \\
\text { de } \\
\text { Hidrográfica }\end{array}$ & $\begin{array}{c}\text { Perímetro } \\
\text { Denagem }\end{array}$ & $\begin{array}{c}\text { Número } \\
\text { de Canais }\end{array}$ & $\begin{array}{c}\text { Comprimento } \\
\text { Total dos } \\
\text { Canais }\end{array}$ & $\begin{array}{c}\text { Comprimento } \\
\text { Médio dos } \\
\text { Canais }\end{array}$ \\
\hline Alto Curso & $170,29 \mathrm{~km}^{2}$ & $58,33 \mathrm{~km}$ & 193 & $204,66 \mathrm{~km}$ & $1,06 \mathrm{~km}$ \\
Médio Curso & $223,14 \mathrm{~km}^{2}$ & $74,84 \mathrm{~km}$ & 213 & $255,94 \mathrm{~km}$ & $1,20 \mathrm{~km}$ \\
Baixo Curso & $98,21 \mathrm{~km}^{2}$ & $51,77 \mathrm{~km}$ & 125 & $131,62 \mathrm{~km}$ & $1,05 \mathrm{~km}$ \\
BHALG & $491,64 \mathrm{~km}^{2}$ & $123,91 \mathrm{~km}$ & 529 & $592,22 \mathrm{~km}$ & $1,12 \mathrm{~km}$ \\
\hline
\end{tabular}

Org.: Os autores, 2014

A partir da distribuição espacial dos canais fluviais e os aspectos físicos da área de estudo, foi identificado para a bacia padrão de drenagem predominantemente retangulardendrítico, devido aos cursos fluviais estabelecerem escoamento superficial de forma encaixada à estrutura dos planos de fratura do substrato geológico, conduzindo ao controle estrutural das drenagens (CHRISFOTOLETTI, 1974).

Com base no comportamento do escoamento hidrológico relacionado à linha geral de escoamento e o ângulo de inclinação das camadas geológicas, definiu-se a rede hidrográfica como subsequentes, posto que, está apresenta o comportamento dos fluxos superficiais controlados conforme o ângulo e as linhas de fraqueza do substrato geológico (CHRISTOFOLETTI, 1974).

Em relação à densidade de drenagem, esta apresenta-se como importante índice em uma análise morfométrica de bacias hidrográficas, pois associa-se ao grau de dissecação topográfica da paisagem frente a ação 
fluvial ou ainda ao número de canais de escoamento disponível. Nesta relação, o comportamento hidrológico das rochas reflete na densidade de drenagem, visto que rochas com menor capacidade de infiltração permitem que haja um maior escoamento superficial e, por conseguinte, a formação de mais canais fluviais (BARATTO e TRENTIN, 2012). Ainda, segundo Christofoletti (1974), este índice se apresenta importante em um estudo e análise de bacias hidrográficas, pois estabelece relação inversa com o comprimento dos rios.

Diante disso, para a análise da densidade de drenagem, Villela e Mattos (1975) indicam os valores de 0,5 $\mathrm{km} / \mathrm{km}^{2}$, para bacias hidrográficas com densidades de drenagem pobres, já índices com valores de $3,5 \mathrm{~km} / \mathrm{km}^{2}$ ou acima deste indicam bacias excepcionalmente bem drenadas. Frente a isso, encontrou-se para a bacia hidrográfica a densidade de drenagem correspondente a $1,20 \mathrm{~km} / \mathrm{km}^{2}$, para os seus setores, não observou-se grandes variações, onde se verificou densidade de drenagem de $1,20 \mathrm{~km} / \mathrm{km}^{2}$ para o alto curso, $1,15 \mathrm{~km} / \mathrm{km}^{2}$ para o médio curso e $1,34 \mathrm{~km} / \mathrm{km}^{2}$ para o baixo curso.

Dessa forma revela-se para a Bacia Hidrográfica do Arroio Lajeado Grande, assim como aos seus setores, uma densidade de drenagem média, sendo possível inferir que o substrato da área constitui-se em geral por uma associação de rochas permeáveis e impermeáveis, o que reflete no escoamento superficial das águas e na geração de novos canais fluviais.

Com base no índice de extensão média do escoamento superficial, Villela e Mattos (1975) assinalam que este se constitui na indicação da distância média do escoamento em superfície para a água da chuva em uma bacia hidrográfica, desde o lugar de queda da água até o ponto mais próximo no leito de um curso fluvial qualquer da bacia, considerando-se o escoamento em linha reta. $\mathrm{O}$ índice permite ainda estabelecer uma relação inversa à densidade de drenagem. Assim, para a bacia hidrográfica em estudo, encontrou-se o valor de $0,21 \mathrm{~km}$ para o comprimento de escoamento superficial. Em relação aos setores, o alto curso apresentou o mesmo valor de $0,21 \mathrm{~km}$, no médio curso o índice foi de $0,22 \mathrm{~km}$ e no baixo curso 0,19 km.

Para a geometria do sistema fluvial, Torres, Neto e Menezes (2012) citando Cunha (1998 apud, TORRES, NETO e MENEZES, 2012), destacam que esta é resultado do ajuste do canal fluvial à sua seção transversal que reflete na inter-relação de variáveis como: a descarga líquida, a carga de sedimentos, a declividade, a largura e profundidade do canal, a velocidade do fluxo e a rugosidade do leito.

Neste sentido, foi avaliada a sinuosidade do curso d'água principal para a bacia hidrográfica, onde se identificou índice de 1,39, no alto curso este estabeleceu-se em 1,40, para o médio curso 1,32 e no baixo curso 1,41. Conforme Villela e Mattos (1975) este índice serve de fator para indicar o quão sinuoso é o canal, o que se estabelece como fator controlador da velocidade do escoamento superficial.

Ademais, quando este índice apresenta valores próximos a 1 , indicase que os canais fluviais tendem a ser retilíneos. Já os valores superiores a 2,0 
indicam que os canais fluviais tendem a ser sinuosos e os valores intermediários indicam formas transicionais, regulares e irregulares. Diante disso, foi identificado para a bacia hidrográfica e para os seus setores um canal de forma transicional e que, segundo Antoneli e Thomaz (2007), este tipo de canal apresenta um transporte mediano de sedimentos.

Para o coeficiente de manutenção, Christofoletti (1774, p. 92) destaca que o índice tem como finalidade fornecer “[...] a área mínima necessária para a manutenção de um metro de canal de escoamento" e, segundo Granell-Pérez (2001) este corresponde ao inverso da densidade de drenagem, o qual permite informar indiretamente a respeito da disponibilidade de água associada ao escoamento superficial. Nesta relação, a bacia hidrográfica apresentou o valor de $833,33 \mathrm{~m}^{2}$ para o escoamento de um metro de canal, para o alto curso este coeficiente apresentou-se também em $833,33 \mathrm{~m}^{2} / \mathrm{m}$, no médio curso o coeficiente foi de $869,56 \mathrm{~m}^{2} / \mathrm{m}$ e para o baixo curso, coeficiente de $746,27 \mathrm{~m}^{2} / \mathrm{m}$.

Com relação às formas de uma bacia hidrográfica, Villela e Mattos (1975) apresentam o tempo de concentração, que representa no tempo em que a água da chuva leva para percorrer as distâncias entre um ponto mais afastado da bacia hidrográfica e o seu exutório.
Em função disso foi avaliado o índice de circularidade que, de acordo com Machado e Torres (2012) possui como valor máximo um $(1,0)$, onde pode-se observar uma bacia hidrográfica totalmente circular. Dessa forma, quando tem-se mais próximo a 1,0 o índice de circularidade, mais circular observa-se a forma da bacia hidrográfica, e de maneira inversa, quanto mais próximo a zero $(0,0)$ for este índice, mais estreita e alongada será a forma da bacia.

Em face disso, a Bacia Hidrográfica do Arroio Lajeado Grande apresentou seu índice de circularidade com o valor de 0,402 , de modo a observar para a bacia uma forma estreita e alongada, permitindo-se indicar uma área pouco propícia a cheias. Assim, nestas condições, as águas que precipitam ao longo da área da bacia apresentam tempos distintos para chegarem ao exutório e, dessa forma não ocorre o extravasamento do leito ao escoarem as águas.

A fim de sistematizar os índices abordados para a caracterização morfométrica da bacia em estudo, apresenta-se a Tabela 3 com a síntese dos parâmetros morfométricos, indicando-se as variáveis abordadas para os setores e para a bacia hidrográfica. 
Tabela 3: Parâmetros morfométricos analisados para a Bacia Hidrográfica do Arroio Lajeado Grande, RS

\begin{tabular}{cccccc}
\hline $\begin{array}{c}\text { Setores e Bacia } \\
\text { Hidrográfica }\end{array}$ & Dd & $\ell$ & Sin & Cm & Ic \\
\hline Alto Curso & $1,20 \mathrm{~km} / \mathrm{km}^{2}$ & $0,21 \mathrm{~km}$ & 1,40 & $833,33 \mathrm{~m}^{2} / \mathrm{m}$ & --- \\
Médio Curso & $1,15 \mathrm{~km} / \mathrm{km}^{2}$ & $0,22 \mathrm{~km}$ & 1,32 & $869,56 \mathrm{~m}^{2} / \mathrm{m}$ & -- \\
Baixo Curso & $1,34 \mathrm{~km} / \mathrm{km}^{2}$ & $0,19 \mathrm{~km}$ & 1,41 & $746,27 \mathrm{~m}^{2} / \mathrm{m}$ & --- \\
BHALG & $1,20 \mathrm{~km} / \mathrm{km}^{2}$ & $0,21 \mathrm{~km}$ & 1,39 & $833,33 \mathrm{~m}^{2} / \mathrm{m}$ & 0,402 \\
\hline
\end{tabular}

Dd: Densidade de drenagem; $\ell$ : extensão média do escoamento superficial; Sin: sinuosidade do curso d'água principal; Cm: Coeficiente de manutenção; Ic: Índice de circularidade.

Org.: Os autores, 2014

\subsection{Análise da Hipsometria}

A Bacia Hidrográfica do Arroio Lajeado Grande apresenta como menor cota altimétrica o nível de $74 \mathrm{~m}$, junto à foz com o rio Ibicuí, em seu baixo curso, localizado na porção norte da bacia. Já a cota de maior altitude é de $246 \mathrm{~m}$, localizada na porção leste da bacia, inferindo-se como um dos pontos divisores d'água, no alto curso, estabelecendo com isso uma amplitude altimétrica de $172 \mathrm{~m}$.

Na Figura 3, é apresentado o mapa hipsométrico da bacia hidrográfica em que foram distribuídas quatro classes hipsométricas de acordo com a variação média das altitudes do terreno em: altitudes inferiores aos $110 \mathrm{~m}$, altitudes entre 110 e $145 \mathrm{~m}$, altitudes entre $145 \mathrm{e}$ $180 \mathrm{~m}$ e altitudes superiores a $180 \mathrm{~m}$.

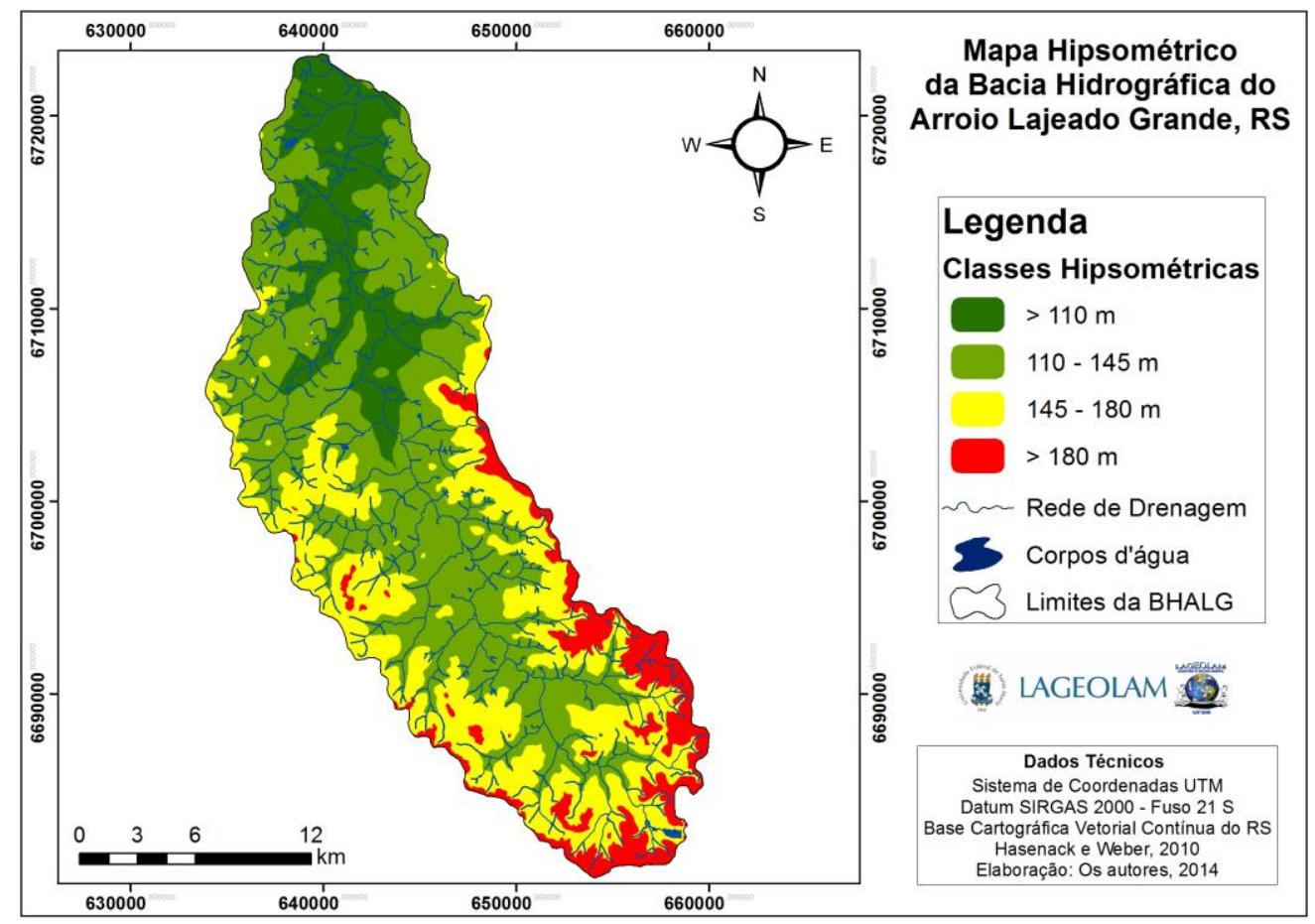

Figura 3: Mapa hipsométrico da Bacia Hidrográfica do Arroio Lajeado Grande, RS Org.: Os autores, 2014 
Observando a Tabela 4 é possível analisar as classes hipsométricas da área de estudo, representadas através de suas áreas em quilômetros quadrados $\left(\mathrm{km}^{2}\right)$ e em valores percentuais $(\%)$.

Tabela 4: Quantificação $\left(\mathrm{km}^{2} \mathrm{e} \%\right)$ das classes hipsométricas da Bacia Hidrográfica do Arroio Lajeado Grande, RS

\begin{tabular}{ccc}
\hline Hipsometria & $\begin{array}{c}\text { Área em quilômetros } \\
\text { quadrados }\left(\mathrm{km}^{2}\right)\end{array}$ & $\begin{array}{c}\text { Área em } \\
\text { porcentagem }(\%)\end{array}$ \\
\hline$<110 \mathrm{~m}$ & 71,00 & 14,44 \\
\hline 110 a $145 \mathrm{~m}$ & 232,62 & 47,32 \\
\hline 145 e $180 \mathrm{~m}$ & 144,25 & 29,34 \\
\hline $180 \mathrm{~m}$ & 43,77 & 8,90 \\
\hline
\end{tabular}

Org.: Os autores, 2014

As altitudes inferiores aos $110 \mathrm{~m}$ apresentam-se distribuídas em área de $71,00 \mathrm{~km}^{2}$, correspondendo a $14,44 \%$ da área da bacia, a classe localiza-se junto às planícies dos cursos fluviais, em especial, associadas ao segmento do curso do rio principal com grandeza igual ou inferior a $5^{\mathrm{o}}$ ordem de drenagem no médio e baixo curso.

As altitudes distribuídas nas cotas que variam de 110 a 145 m apresentamse em maior área, onde se espacializam nos três setores da bacia totalizando área de $232,62 \mathrm{~km}^{2}$, o que representa $47,32 \%$ da área total da bacia hidrográfica.

Com relação à classe, distribuída nas cotas altimétricas que variam entre $145 \mathrm{e}$ $180 \mathrm{~m}$, apresentam-se localizas principalmente no alto e médio curso, onde representam área de 144,25 km², equivalendo a $29,34 \%$ da área da bacia. Para esta classe pode-se destacar associada à ocorrência de cabeceiras de drenagem, no médio e alto curso da bacia hidrográfica.

Por fim, as elevações superiores a $180 \mathrm{~m}$ encontram-se distribuídas no médio e alto curso, em porções a leste, oeste e sul da bacia, em área igual a $43,77 \mathrm{~km}^{2}$, representando $8,90 \%$ da área de estudo. Nestes locais se estabelecem os limites da área da bacia hidrográfica junto aos pontos divisores d'água do terreno.

\subsection{Análise da Declividade das Vertentes}

A declividade das vertentes segundo Florenzano (2008) corresponde à inclinação do relevo em relação ao plano horizontal. Neste contexto, De Nardin e Robaina (2005) destacam que a análise destas apresenta-se com relevância no estudo das potencialidades da área em que relacionam-se aos tipos de uso e ocupação da terra.

Frente a isso, foram estabelecidas quatro classes para as declividades da bacia hidrográfica: menores que $2 \%$, entre 2 e $5 \%$, entre 5 e $15 \%$ e superiores a $15 \%$, conforme representadas no mapa de declividade, Figura 4. 


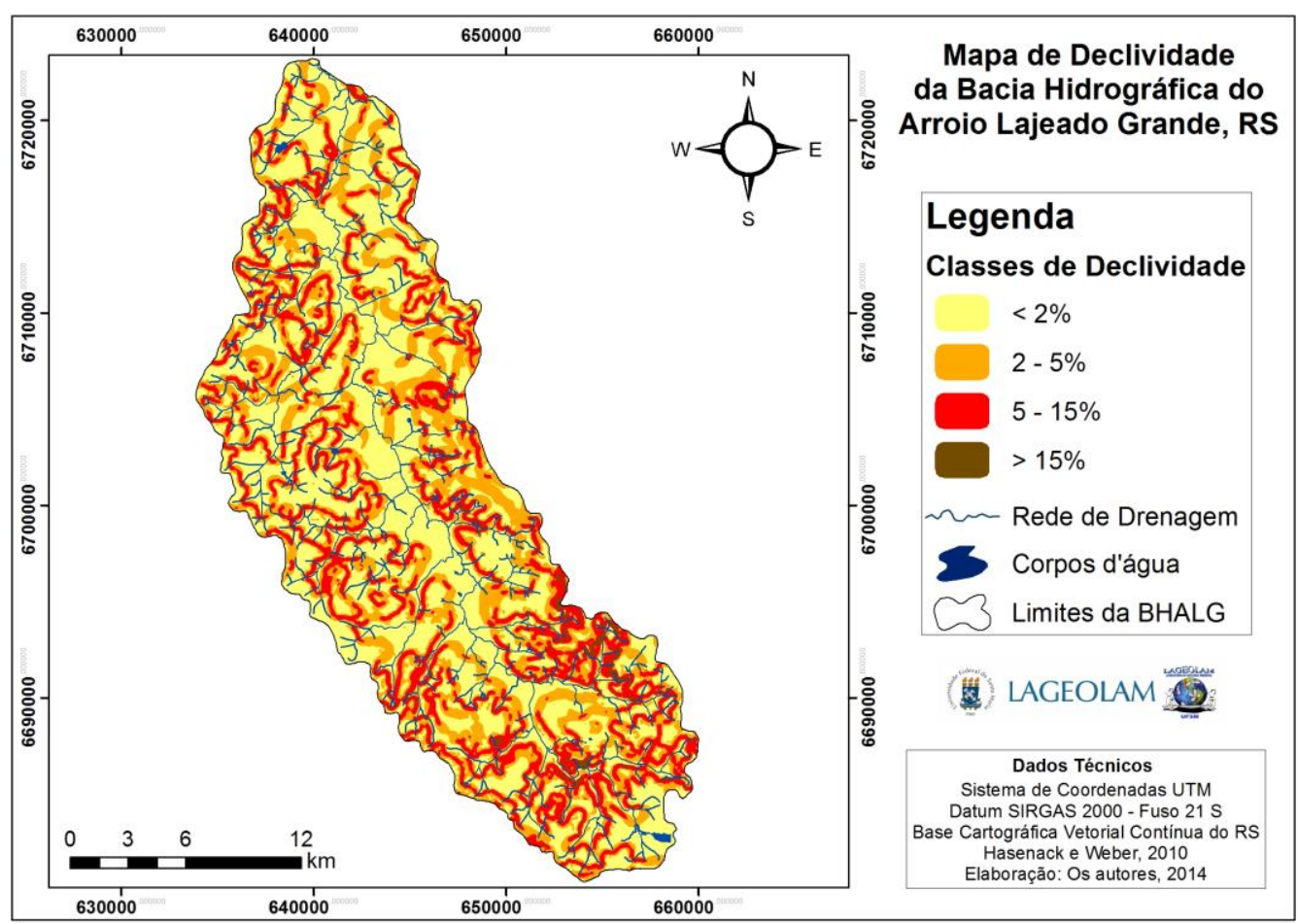

Figura 4: Mapa de declividade da Bacia Hidrográfica do Arroio Lajeado Grande, RS Org.: Os autores, 2014

Na Tabela 5, destaca-se a distribuição das classes de declividade, da Bacia Hidrográfica do Arroio Lajeado Grande por área em quilômetros quadrados $\left(\mathrm{km}^{2}\right) \mathrm{e}$ em valores percentuais (\%).

Tabela 5: Quantificação $\left(\mathrm{km}^{2}\right.$ e \%) das classes de declividade da Bacia Hidrográfica do Arroio Lajeado Grande, RS

\begin{tabular}{ccc}
\hline Declividades & $\begin{array}{c}\text { Área em quilometros } \\
\text { quadrados }\left(\mathrm{km}^{2}\right)\end{array}$ & $\begin{array}{c}\text { Área em } \\
\text { porcentagem }(\%)\end{array}$ \\
\hline$<2 \%$ & 233,12 & 47,42 \\
\hline $2-5 \%$ & 150,86 & 30,68 \\
\hline $5-15 \%$ & 103,70 & $21,09 \%$ \\
\hline$>15 \%$ & 3,96 & 0,81 \\
\hline
\end{tabular}

Org.: Os autores, 2014

As declividades inferiores a $2 \%$ apresentam-se em maior área na bacia, ocupando 233,12 $\mathrm{km}^{2}$, o que compreende-se em $47,42 \%$ da área total desta. Esta classe encontra-se distribuída em todas as poções da área de estudo, principalmente associadas próximas às drenagens. Estes locais caracterizam-se por serem áreas planas onde ocorrem processos de acumulação de sedimentos fluviais, e por serem áreas suscetíveis a inundações, decorrentes do extravasamento das águas do canal principal.

As declividades com variação entre $2 \%$ e $5 \%$ constituem-se como a segunda 
classe maior em área na bacia, distribuída em 150,86 km², equivalendo a $30,68 \%$ da área total da bacia hidrográfica. Esta classe se encontra espacializada em todas as porções da área de estudo, em especial, nas áreas de planícies, nas quais apresentam maior abrangência no médio e alto curso.

Para a classe de declividades entre $5 \%$ e $15 \%$, localizadas principalmente no alto curso, ocorrem em área de 103,70 $\mathrm{km}^{2}$, representando $21,09 \%$ da área da bacia. Nestes locais é presente um relevo ondulado associado às colinas, em que passam a ocorrer de forma mais intensa processos erosivos acelerados associados a rochas freáveis.

Quanto a classe de declividades superiores a 15\%, estas apresentam-se em menores porções na área da bacia hidrográfica, associada a um relevo, em geral, ondulado, com formas íngremes e escarpadas. Espacialmente localizam-se em maior densidade no alto curso da bacia, totalizando área de $3,96 \mathrm{~km}^{2}$, o que corresponde a $0,81 \%$ da área total da bacia hidrográfica.

\subsection{Análise do Comprimento de Vertentes}

O comprimento de vertentes exerce grande influência sobre as características do terreno, tais como a capacidade de infiltração, o tempo para escoamento superficial e na capacidade erosiva, apresentando-se como importante parâmetro morfométrico para ser avaliado nos estudos geomorfológicos (RECKZIEGEL e ROBAINA, 2006).

Neste sentido, foi realizada a análise dos comprimentos das vertentes para a Bacia Hidrográfica do Arroio Lajeado Grande, de modo a individualizar a ocorrência de três classes de comprimentos de vertentes para a área de estudo, sendo representadas em: vertentes curtas, nas quais apresentam comprimentos definidos dentro do intervalo de $246 \mathrm{~m}$ a 644,92 $\mathrm{m}$, vertentes médias entre intervalo de 644,92 $\mathrm{m}$ até $1043,83 \mathrm{~m}$ e vertentes longas com comprimentos de vertentes superiores a 1043,83 m (Tabela 6).

Tabela 6: Quantificação (\%) dos comprimentos de vertentes da Bacia Hidrográfica do Arroio Lajeado Grande, RS

\begin{tabular}{cccc}
\hline $\begin{array}{c}\text { Setores e } \\
\text { Bacia } \\
\text { Hidrográfica }\end{array}$ & Vertentes Curtas & Vertentes Médias & $\begin{array}{c}\text { Vertentes } \\
\text { Longas }\end{array}$ \\
\hline Alto Curso & $51,43 \%$ & $34,29 \%$ & $14,28 \%$ \\
Médio Curso & $45,71 \%$ & $34,29 \%$ & $20,00 \%$ \\
Baixo Curso & $34,29 \%$ & $42,86 \%$ & $22,85 \%$ \\
BHALG & $43,81 \%$ & $37,14 \%$ & $19,05 \%$ \\
\hline
\end{tabular}

Org.: Os autores, 2014

Para a bacia hidrográfica, ocorrência de vertentes curtas e identificou-se a predominância de vertentes médias dentre as quais 
apresentaram valores percentuais de $43,81 \%$ para a ocorrência de vertentes curtas e $37,14 \%$ para vertentes médias, já os $19,05 \%$ restantes estabelecendo-se em vertentes longas.

Relacionado aos setores da bacia hidrográfica, foi observado no alto curso a prevalência de um relevo associado a vertentes curtas ocorrendo $51,43 \%$ das formas analisadas, sendo seguido por vertentes médias em 34,29\% e vertentes longas em 14,28\%. A predominância de vertentes curtas no alto curso ocorre pelo fato desta área da bacia hidrográfica possuir as maiores declividades no terreno e apresentar sua rede de drenagem com os canais fluviais encaixados ao relevo estabelecendo dessa forma as vertentes mais curtas.

No médio curso, seguiu-se um mesmo padrão em que predominaram vertentes curtas, em $45,71 \%$ e vertentes médias em 34,29\% das formas do relevo, despondo-se em menores valores percentuais vertentes longas em 20,00\%. No entanto, deve-se destacar que neste setor observa-se uma mudança nos valores percentuais para os comprimentos das vertentes, onde passa a ocorrer uma menor frequência para as vertentes curtas, associando-se a um sensível aumento para a ocorrência de vertentes longas.

Em relação ao baixo curso, ocorreu uma prevalência de vertentes médias e vertentes curtas respectivamente em $42,86 \%$ e $34,29 \%$ para as formas do relevo, apresentando o valor de 22,85\% para as vertentes longas. Associado a isso, observa-se no baixo curso da bacia hidrográfica uma relação contrária ao que ocorre no alto e médio curso onde prevalecem em maioria vertentes curtas.
Este fato ocorre porque neste setor, o seu relevo apresenta-se mais plano, refletindo com isso, em uma maior frequência de vertentes médias.

\section{Considerações Finais}

O processo de análise dos parâmetros morfométricos da Bacia Hidrográfica do Arroio Lajeado Grande compreendeu-se de forma eficaz, no qual permitiu-se caracterizar a rede de drenagem e o relevo da área, através de métodos quantitativos, possibilitando dessa forma, a compreensão dos processos de dinâmica superficial recorrentes na bacia hidrográfica.

A partir disso, considerando-se os parâmetros avaliados, denota-se a influência que a constituição rochosa desempenha na área, inferindo-se diretamente sobre a distribuição e espacialização dos segmentos de canais fluviais refletidos no padrão de drenagem, densidade de drenagem e coeficiente de manutenção. Ademais, analisada a sinuosidade do curso d'água principal pode-se indicar uma carga mediana de sedimentos e ainda, por meio do estudo dos parâmetros do relevo e do índice de circularidade, permite-se abstrair uma bacia hidrográfica com uma forma estreita e alongada, sendo uma área não muito suscetível ao extravasamento do leito principal.

Com base nos setores da bacia hidrográfica delimitados no alto, médio e baixo curso, de maneira geral, apresentam diferenças quanto ao comportamento da topografia. No entanto, em relação aos índices morfométricos analisados, estes não 
apresentaram grandes distinções, com exceção do comprimento das vertentes que relacionam-se diretamente com as condições topográficas.

Dessa maneira, diante do que foi abordado aponta-se que os trabalhos norteados através de parâmetros morfométricos, associam-se aos estudos geomorfológicos e geoambientais, nos quais, possibilitam que sejam aplicadas estas informações como auxilio ao planejamento, servindo em ações prognósticas e na orientação para o uso e ocupação da terra para as áreas de estudo.

\section{Agradecimentos}

Projetos FAPERGS (Fundação de Amparo à Pesquisa do Estado do Rio Grande do Sul) e CNPq (Conselho Nacional de Desenvolvimento Científico e Tecnológico).

\section{Referências}

ALVES, F. S. Estudos Fitogeográficos na Bacia Hidrográfica do Arroio Lajeado Grande - Oeste do RS. Santa Maria: UFSM/PPGEO, 2008. 106 f. Dissertação (Mestrado).

ANTONELI, V.; THOMAZ, E. L. Caracterização do meio físico da bacia do Arroio Boa Vista. Caminhos da Geografia, Uberlância, v. 8, n. 21, p. 4658, junho 2007.

BARATTO, D. S.; TRENTIN, R. Análise das Unidades de Relevo da Bacia Hidrográfica do Arroio Puitã (RS). REVISTA GEONORTE, Edição Especial, V.3, N.4, p. 543-555, 2012.
BOTELHO, R. G. M.; SILVA, A. S. D. Bacia Hidrográfica e Qualidade Ambiental. In: VITTE, A. C.; GUERRA, A. J. T. Reflexões sobre a geografia física no Brasil. Rio de Janeiro: Bertrand Brasil, 2004.

CHRISTOFOLETTI, A. Geomorfologia. São Paulo: Edgard Blücher, Ed. da Universidade de São Paulo, 1974.

DE NARDIN, D.; ROBAINA, L. E. S. Mapeamento de Unidades do Relevo no Oeste do RS: O Caso da Bacia Hidrográfica do Arroio Miracatú. Anais do XI Sinpósio Brasileiro de Geografia Física Aplicada, São Paulo, USP, 2005.

FLORENZANO, T. G. Introdução à Geomorfologia. In: FLORENZANO, T. G. (org.). Geomorfologia: conceitos e tecnologias atuais. São Paulo: Oficina de Textos, 2008.

GRANELL-PÉREZ, M. C. Trabalhar geografia com as cartas topográficas. Ijuí, Ed. Unijuí, 2001.

HASENACK, H.; WEBER, E. Base Cartográfica Vetorial Contínua do Rio Grande do Sul. Escala 1:50.000. Porto Alegre: UFRGS, 2010.

IPT. Mapeamento geomorfológico do Estado de São Paulo. São Paulo. Escala 1:500.000. 130p. 2v. (IPT - Publicações, 1183). 1981.

MACHADO, P. J. O.; TORRES, F. T. P. Introdução à hidrogeografia. São Paulo: Cengage Learning, 2012. 
MOREIRA, C. V. R.; NETO, A. G. P. Clima e Relevo. In: OLIVEIRA, A. M. S.; BRITO, S. N. A. Geologia de Engenharia. São Paulo: Associação Brasileira de Geologia e Engenharia, 1998.

PAULA, P. M. Mapeamento de Unidades Litomorfológicas em Bacias Hidrográficas com Processos de Arenização, Alegrete - RS. Universidade Federal do Rio Grande o Sul, Porto Alegre, 2006. 69 f. Dissertação (Mestrado).

RECKZIEGEL, E. W; ROBAINA, L. E. S. Estudo de Parâmetros Morfométricos do Relevo e da Rede de Drenagem da Área Situada Entre os Rios Jaguari e Ibicuí no Município de São Vicente do Sul - RS. Anais do VI Simpósio Nacional de Geomorfologia: Geomorfologia Tropical e Subtropical: processos, métodos e técnicas. Goiânia-GO, 2006.

ROBAINA, L. E. S.; TRENTIN, R.; BAZZAN, T.; RECKZIEGEL, E. W.; VERDUM, R.; DE NARDIN, D. Compartimentação Geomorfológica da Bacia Hidrográfica do Ibicuí, Rio Grande do Sul, Brasil: Proposta de Classificação. Revista Brasileira de Geomorfologia, v.11, n.2, p.11-23, 2010.

SANGOI, D. S.; TRENTIN, R.; ROBAINA, L. E. S.; PIRES, C. A. F. Mapeamento de "Landforms" na bacia do Rio Inhacundá, São Francisco de Assis (RS). Geosul, Florianópolis, v. 18, n. 36, p 151-167, jul./dez. 2003.

TORRES, F. T. P.; NETO, R. M.; MENEZES, S. O. Introdução à geomorfologia. São Paulo, Cengage Learning, 2012.
TRENTIN, R.; RECKZIEGEL, B. W.; DAL'ASTA, A. P.; ROBAINA, L. E. S. Mapeamento das Unidades de Relevo, com Base em Parâmetros Morfométricos, no Alto Curso da Bacia Hidrográfica do Rio Itu, RS. Anais do $V$ Simpósio Nacional de Geomorfologia, I Encontro Sul-Americano de Geomorfologia. Santa Maria, UFSM, 2004.

VILLELA, S. M.; MATTOS, A. Hidrologia Aplicada. São Paulo: McGraw-Hill do Brasil, 1975. 